Review Article

\title{
Zoster sine herpete: a review
}

\author{
Junli Zhou' ${ }^{1}$, Juan $\mathrm{Li}^{1}$, Lulin $\mathrm{Ma}^{1}$, and Song $\mathrm{Cao}^{1,2}$ \\ 'Department of Pain Medicine, Affiliated Hospital of Zunyi Medical University, Zunyi, China \\ ${ }^{2}$ Guizhou Key Laboratory of Anesthesia and Organ Protection, Zunyi Medical University, Zunyi, China
}

Received April 6, 2020

Revised May 30, 2020

Accepted June 2, 2020

Handling Editor: Kyung Hoon Kim

\section{Correspondence}

Song Cao

Department of Pain Medicine, Affiliated

Hospital of Zunyi Medical University, 149

Dalian Street, Zunyi 563000, Guizhou,

China

Tel: +8618212170434

Fax: +860851-28608835

E-mail: caosong4321@163.com
Zoster sine herpete (ZSH) is one of the atypical clinical manifestations of herpes zoster (HZ), which stems from infection and reactivation of the varicella-zoster virus (VZV) in the cranial nerve, spinal nerve, viscera, or autonomic nerve. Patients with ZSH display variable symptoms, such as neuralgia, however, different from $\mathrm{HZ}$, ZSH show no zoster, which makes clinical diagnosis difficult. ZSH not only causes initial symptoms, such as neuropathic pain in the affected nerve, Bell palsy, and Ramsay Hunt syndrome, but also postherpetic neuralgia and fatal complications such as VZV encephalitis and stroke. The misdiagnosis of ZSH and tardy antiviral treatment may lead to severe ZSH sequelae. We review the publications related to ZSH, especially its diagnosis with VZV DNA and/or anti-VZV immunoglobulin (IgG and IgM). More work about ZSH, especially ZSH epidemiological survey and guidelines for its diagnosis and treatment, are needed because most of the present studies are case reports.

Key Words: Antiviral Agents; Diagnosis; Herpes Zoster; Herpesvirus 3, Human; Infections; Neuralgia, Postherpetic; Therapeutics; Virus Diseases; Zoster Sine Herpete.

\section{INTRODUCTION}

Zoster sine herpete (ZSH) is one of the atypical clinical manifestations of herpes zoster (HZ) [1,2]. ZSH and $\mathrm{HZ}$ are both induced by reactivation of the neurotropic varicellazoster virus (VZV) [3,4]. VZV infection and reactivation in the nervous system, such as cranial nerve and spinal nerve, can spread to the innervated target tissue (skin, cornea, laryngeal mucosa, etc.) and cause rash (shingles) eruption. Once the shingle appears, the diagnosis of $\mathrm{HZ}$ is apparent from its clinical manifestation. Unfortunately, VZV reactivation does not always cause shingles, and can occur in the enteric nervous system, such as the viscera or autonomic nerve, which do not project to the skin. This kind of reactivation with no shingles after the initial VZV infection is called ZSH [5].
ZSH is likely to be missed or misdiagnosed, and patients may not receive timely antiviral treatment. This causes continuous activation of the VZV, which may induce lasing herpetic neuralgia, and even postherpetic neuralgia (PHN) if much damage was cause to the affected nerves [6]. More seriously, continuous VZV reactivation can lead to fatal sequelae such as encephalitis, cerebrovasculopathy, and stroke $[7,8]$. The literature about ZSH manifestations, especially the diagnosis of ZSH with VZV reactivation, are reviewed in this article.

\section{THE EPIDEMIOLOGY OF HZ AND ZSH}

At present, there is no epidemic data about ZSH. However, considering the high infection rate of VZV, and the epide- (a) This is an open-access article distributed under the terms of the Creative Commons Attribution Non-Commercial License (http://creativecommons.org/licenses/by-nc/4.0/), which permits unrestricted non-commercial use, distribution, and reproduction in any medium, provided the original work is properly cited.

(C) The Korean Pain Society, 2020
Author contributions: Junli Zhou: Writing/manuscript preparation; Juan Li: Investigation; Lulin Ma: Investigation; Song Cao: Study conception. 
miology of $\mathrm{HZ}$ and PHN in populations, the incidence of ZSH cannot be low.

In America, there are almost one million cases of $\mathrm{HZ}$ each year, with an annual rate of $0.3 \%$ to $0.4 \%[9,10]$. In China, the prevalence of $\mathrm{HZ}$ is $7.7 \%$ in hospital patients aged $\geq 40$ years [11]. In the old ( $\geq 50 \mathrm{yr}$ ), immunocompetent, unvaccinated population, the $\mathrm{HZ}$ incidence rate was $\sim 10 / 1,000$ person-years [12]. In North America and Europe, more than $95 \%$ of young adults are positive for the VZV, which means they are at risk for ZSH and HZ [13]. Of note, the incidence of $\mathrm{HZ}$ is expected to increase in the future because of the gradually aging world, and developments of medicine (e.g., immunosuppressive agents) $[14,15]$. Therefore, ZSH is very likely underreported and underrated, which may be the reason of some neuropathic pain of unknown origin.

\section{PATHOGENESIS OF ZSH}

$\mathrm{VZV}$, the pathogen of ZSH and $\mathrm{HZ}$, is transmitted by direct contact or by inhalation of aerosols from vesicular fluid or infected respiratory tract secretions [9]. The VZV can travel retrogradely along sensory neuron fibers to the spinal dorsal root ganglion or cranial ganglion and stay dormant [16]. When the VZV-specific immunity decreases, the latent virus in the ganglions reactivates, replicates, and then various HZ or ZSH symptoms appear [4]. Many factors affecting cellular immunity may cause the reactivation of the VZV [17]. These risk factors for VZV reactivation include: old age, cellular immunodeficiency, genetic susceptibility, trauma, systemic diseases (such as diabetes, kidney disease, fever, hypertension, etc.), mental stress, fatigue, and so on [18-20].

The specific mechanisms of VZV reactivation are not fully understood [21]. VZV-specific memory T cells are present after the initial recovery from VZV infection. However, as time goes by, the immune function of memory $\mathrm{T}$ cells declines. When it falls below the theoretical "zoster threshold", the risk of ZSH or HZ increases accordingly [22]. After being recognized by its recognition receptors, the VZV activates the signaling in the body and induces the gathering of inflammatory cells to combat the VZV, and indirectly activates $\mathrm{T}$ cells, which jointly cause the damage of skin and nerve tissues, and result in neuralgia and other symptoms of ZSH or HZ [23].

Evidence suggests that persistent radicular pain from ZSH can be caused by chronic activation of the VZV and ganglionitis. In a patient who had experienced chronic trigeminal neuralgia for more than 1 year, the trigeminal ganglionic mass was removed and the pathological and virological analyses discovered active VZV ganglionitis [24].
In another study, active VZV ganglionitis was found in the trigeminal ganglia of a patient who experienced chronic trigeminal neuralgia for months before death [25]. Using human dorsal root ganglia xenografts in immunodeficient mice, Zerboni and Arvin [26] demonstrated VZV replication in mechanoreceptive neurons; They also found that the VZV in the dorsal root ganglia triggers release of proinflammatory cytokines that cause neuronal damage. These findings may help to explain the neurologic sequelae in $\mathrm{ZSH}, \mathrm{HZ}$, and $\mathrm{PHN}$ patients.

\section{CLINICAL FEATURES}

Evidence indicates that VZV infection and reactivation are more common than previously realized. VZV reactivation, displaying no cutaneous vesicles, has been demonstrated in $8 \%$ to $25 \%$ of patients with acute peripheral facial palsy by serological examination [27]. The VZV latency and reactivation in neurons, including those of the enteric nervous system that do not project to the skin, can cause serious and variable ZSH clinical features [28]. ZSH patients not only complain of different kinds of neuropathic pain, but also display lesions at hidden places other than the skin, as well as various manifestations of nerve injury $[29,30]$.

As early as 1958, Lewis [5] proposed a diagnosis method of ZSH in patients with radicular pain in the skin, based on a variety of syndromes: (1) unilateral segmental pain of a sclerotomal or dermatomal type, or both, with complete recovery in a few weeks; (2) certain painful unilateral muscular paresis of obscure origin; (3) unilateral segmental pain associated with certain visceral disturbances of short duration and complete resolution; (4) unilateral ophthalmic neuralgia with involvement of the eyeball, or with paresis of the ocular muscles, or both; (5) unilateral otalgia without evidence of middle-ear disease and associated with facial palsy, hyperacousis, or loss of taste sensation on the anterior two-thirds of the tongue; (6) cases presenting as an acute labyrinthitis, or Menier's syndrome, with evidence of the involvement of adjacent nerves, particularly the seventh cranial nerve; (7) unilateral paralysis of the soft palate, pharyngeal muscles, or vocal cord of obscure origin, especially when associated with otalgia or with an inflammatory reaction in, or around, the entrance to the larynx.

\section{Neuropathic pain}

Although there is no classic cutaneous presentation of $\mathrm{HZ}$ in ZSH patients, dermatomal neuropathic pain or pruritus is common in ZSH cases [31]. Pain from ZSH may present as unilateral, radial, or localized [32,33]. Important in the 
recognition of syndromes of ZSH is an appreciation of the characters of the pain in HZ [5]. The pain can be a deep boring or twisting pain arising in muscles, joints, etc., which is called "sclerotomal pain"; or a superficial, burning pain in or near the skin called "dermatomal pain" [5].

Compared with pain in $\mathrm{HZ}$, ZSH patients were reported to suffer more serious pain [6]. At the beginning, one month, and three month after the onset of symptoms, the pain ZSH patients experienced was more severe than that of HZ patients [6]. However, why the pain intensity is higher in ZSH patients is unknown. The authors thought that in ZSH patients, the VZV replication may take place mainly the in sensory ganglia and nerve root, and the innate epidermal immune response reduced the production of interferon- $\alpha$, tumor necrosis factor- $\alpha$ and interleukin$1 \alpha$, and prevented the spread of the VZV in the skin [34]. In addition, memory $\mathrm{T}$ cells containing skin-homing receptors may cooperate with the innate epidermal immune response, and limit the VZV reactivation and replication in the skin. Furthermore, ZSH patients showed poorer reactivity to antiviral drugs, and their serum VZV DNA content was higher than that of HZ patients after one month, suggesting the effects of antiviral drugs are inconsistent between ZSH and HZ patients [6].

\section{Lesions at the mucosa, auditory canal, and viscera}

Lesions at the mucosa such as the larynx [35], the auditory canal [36], the cornea of the eye [37], and lesions at the viscera such as the stomach [38] and intestine [32] can be induced by VZV reactivation. For example, unexplained abdominal pain may be related to $\mathrm{ZSH}$, because salivary VZV DNA was detected in 6 of 11 patients of this type, 11 of 16 patients with zoster or varicella, and 2 of $2 \mathrm{ZSH}$ patients. However, the healthy controls $(n=20)$ and patients with unrelated gastrointestinal disorders $(n=8)$ were all negative for VZV DNA detection [38]. These results indicate that ZSH may be the reason for the abdominal pain. Patients with mucosal lesions in the larynx, with a sore throat, dysphagia, and hoarseness were VZV DNA positive after detecting exudates taken from the pharyngeal mucosal lesions [35]. Patients in these studies all responded to, and benefited from, antiviral therapy.

\section{DIAGNOSIS}

Symptoms and signs of ZSH can be covert, and ZSH should be considered in patients with a history of radicular pain, peripheral facial palsy, or muscle paralysis without a rash, especially when other causes are excluded. For example, $\mathrm{ZSH}$ of the trigeminal nerve should be considered in patients with neuropathic pain in the trigeminal nerve innervating area, if they do not demonstrate other appreciable findings such as tumor or HZ [34]. A high level of suspicion of ZSH is needed for prompt diagnosis and treatment in undiagnosed patients with neuropathic pain, especially in immunosuppressed patients, and it is very necessary to take a thorough medical history including recurrent pain and recent use of medications.

Diagnosis with symptom alone may lead to misdiagnosis, and thus it is necessary to find evidence of VZV reactivation to diagnose $\mathrm{ZSH}$, which primarily depends on laboratory investigation [6]. Several kinds of approaches are available to confirm VZV infection. For a while, the "gold standard" for VZV infection detection was virus isolation, which is costly and time consuming. In addition, the VZV is a labile virus, so cultures can fail in VZV infected patients. Therefore, VZV isolation is rarely used for confirming infection today [39]. At present, there are two widely used methods to detect VZV reactivation: VZV DNA detection with polymerase chain reaction (PCR), and an enzyme linked immunosorbent assay (ELISA) examination of anti-VZV antibodies, i.e., anti-VZV immunoglobulin (IgG and IgM) (Table 1).

\section{Diagnosis with VZV DNA}

PCR exponentially amplify VZV DNA, and the signal of VZV DNA content can be amplified and detected. The first

Table 1. VZV DNA- and Anti-VZV Antibody-based Detection of VZV Reactivation in ZSH

\begin{tabular}{|c|c|c|c|}
\hline \multirow{2}{*}{ Detection situation } & \multirow{2}{*}{ VZV DNA } & \multicolumn{2}{|c|}{ Anti-VZV antibody } \\
\hline & & Anti-VZV IgG & Anti-VZV IgM \\
\hline Sample & CSF, serum, saliva & CSF, serum & CSF, serum \\
\hline Detection method & Polymerase chain reaction & ELISA & ELISA \\
\hline Advantage & High sensitivity & Convenient kit & Convenient kit, reflect early reactivation \\
\hline Disadvantage & $\begin{array}{l}\text { Could be false negative results for latent } \\
\text { VZV reactivation }\end{array}$ & $\begin{array}{l}\text { Could be false negative results for early } \\
\text { VZV reactivation }\end{array}$ & $\begin{array}{l}\text { Early antibodies, narrow time window for } \\
\text { early VZV reactivation detection }\end{array}$ \\
\hline
\end{tabular}

VZV: varicella-zoster virus, ZSH: zoster sine herpete, IgG: immunoglobulin G, IgM: immunoglobulin M, CSF: cerebrospinal fluid, ELISA: enzyme linked immunosorbent assay. 
two virologically confirmed cases of ZSH were verified by detection of VZV DNA in cerebrospinal fluid (CSF) with PCR [33]. To date, ZSH is widely diagnosed with PCR to confirm the reactivation of the VZV with different samples, such as swabs of the lesion site, exudate, CSF, blood, tissues from autopsies or biopsies, and saliva [40-44].

Saliva is an ideal sample because its collection is easy and noninvasive and has been successfully used for VZV DNA detection in $\mathrm{ZSH}$ and $\mathrm{HZ}$ patients $[45,46]$. However, further studies on the sensitivity and accuracy of VZV DNA detection in saliva are indispensable [39].

\section{Diagnosis with IgG and/or IgM}

In ZSH patients, rising anti-VZV antibody titers serve as a marker for active viral infection $[47,48]$. Besides VZV DNA detection, the presence of anti-VZV IgG antibody in the CSF $[2,29,31,49,50]$ or serum $[44,51-53]$ can be used to diagnose ZSH. Anti-VZV IgG in the CSF, and the reduced serum/CSF ratios of VZV IgG compared with the normal level of serum/CSF ratios for albumin and total IgG, reflect the intrathecal synthesis of anti-VZV IgG [54].

At the beginning of VZV reactivation, anti-VZV IgM elevates in the CSF or serum, which can be used to confirm the reactivation of the VZV. However, even at the beginning of ZSH, IgM is not as sensitive as IgG in ZSH diagnosis. In a cohort of $45 \mathrm{ZSH}$ patients with acute peripheral facial paralysis that occurred within 7 days, all of the patients were anti-VZV IgG positive after blood tests; however, only 7 patients (15.6\%) were anti-VZV IgM positive [51]. More studies are warranted to compare the efficacy and time window of anti-VZV IgM and IgG tests, and whether samples (i.e., CSF and serum) affect the results of IgM/IgG tests.

\section{PCR or ELISA?}

Although VZV DNA detection with PCR and VZV IgG and IgM detection with ELISA are widely used to confirm VZV reactivation, these two detection methods have their own advantages and disadvantages, which have been summarized in Table 1.

In one study, using oropharyngeal swabs, VZV DNA was detected with PCR in 6/36 patients with acute peripheral facial palsy at their initial visit (2 to 4 days after facial palsy), while the anti-VZV IgM and IgG antibody titers were not increased significantly. Interestingly, after a while, in some of the patients, VZV DNA became negative when the VZV-specific antibody response appeared. These results indicate that at the beginning of ZSH, detection of VZV DNA is more sensitive than anti-VZV antibodies in patients with acute peripheral facial palsy [27].
However, in some different situations, such as the VZV vasculopathy, the intrathecally synthesized VZV IgG was a superior parameter as compared to VZV DNA in the CSF [55], and it is reported that in myelopathy patients, CSF was negative for VZV DNA detection [56,57]. In a ZSH patient, whose CSF was VZV DNA negative, anti-VZV IgG was, in fact, positive and evidently reduced serum/CSF ratios of anti-VZV IgG, which indicates intrathecal synthesis [58].

These comparisons indicate that the outcome of VZV DNA or anti-VZV antibodies detection is related to the sample type and the detection timepoint during the course of ZSH. More studies are needed to determine the better method and sample, as well as the best timepoint to confirm if the VZV reactivation exists in different kind of ZSH patients. Until then, the CSF should be examined for both VZV DNA and anti-VZV IgG antibody in suspected ZSH patients [58]. For example, in a case of ZSH with thoracic pain distribution, the diagnosis was confirmed by detections of VZV DNA in blood mononuclear cells and anti-VZV IgG antibody in the CSF [59].

\section{COMPLICATIONS}

Because of VZV reactivation, ZSH can cause many neurological diseases $[29,49,60]$. In fact, more and more neurological disorders have been found to be associated with $\mathrm{VZV}$ reactivation in $\mathrm{ZSH}$. Some of them are even fatal, especially when VZV reactivation and invasion take place in the central nervous system.

\section{Fatal complications}

Some complications of ZSH, such as the meningitis or meningoencephalitis [7,61-63], myelopathy [49,60], vasculopathy $[8,64]$ etc. are fatal if the VZV reactivation is not noticed and ZSH is misdiagnosed. Among them, VZV cerebrovasculopathy is caused by viral infection of the arteries, leading to pathological vascular remodeling and an ischemic or hemorrhagic stroke, with a mortality rate of $25 \%$, and one-third of patients with virology-proven VZV vascular disease had no previous rash [8]. In addition, by reactivating and infecting the meninges, brain parenchyma, and nerve roots, the VZV can cause VZV meningitis, VZV encephalitis, and VZV radiculitis [49]. VZV meningoencephalitis can manifest as mild aseptic meningitis but also as severe encephalitis with edema, brain necrosis, and demyelination [61]. The mortality rate of VZV encephalitis is as high as 9\% [65]. Besides, VZV meningoradiculitis can be lethal as reported [66]. VZV myelopathy can present as a fatal myelitis, mostly in immunocompromised individuals. Postmortem analyses of the spinal cord from 
fatal cases have revealed a apparent invasion of the VZV in the parenchyma with associated inflammation [67] and, in some instances, spread of the virus to adjacent nerve roots.

\section{PHN}

As the most common sequela of $\mathrm{HZ}$ or $\mathrm{ZSH}, \mathrm{PHN}$ is a typical neuropathic pain that is associated with peripheral and central sensitization [68]. Most of the reports of PHN appear after HZ, however, surprisingly, Drago et al. [6] found that compared with typical $\mathrm{HZ}$ patients, there was a higher rate of PHN development for ZSH patients. The structural basis of PHN may include changes of neuroplasticity caused by lasing VZV reactivation in ZSH or HZ [69]. For example, chronic VZV activation and ganglionitis may be the cause of PHN [25]. Of note, PHN should be considered if there is recurrent radioactive neuropathic pain in the same innervation area, and the initial pain could be a symptom of $\mathrm{ZSH}$.

To differentiate preherpetic neuralgia resulting from ZSH from PHN, by clinical findings alone, is difficult, because both ZSH and PHN patients do not indicate vesicular eruption. In this case, clinical history and/or findings from serologic examination of the VZV will facilitate an appropriate diagnosis. It is important to distinguish PHN from $\mathrm{ZSH}$ because the treatment of $\mathrm{ZSH}$ is different from that of PHN. For ZSH, acyclovir or valaciclovir administration is essential, but the treatment for PHN is mainly aimed at pain and the symptom control.

\section{PREVENTION}

$\mathrm{HZ}$ vaccine is a major breakthrough for the prevention of $\mathrm{HZ}$. It should be able to effectively reduce ZSH and complications such as PHN caused by HZ and ZSH. In 2006, zoster vaccine live (Zostavax) has been recommended for those $\geq 60$ years old, who have no contraindications, and in 2011 , the indication has been extended to everyone $\geq$ 50 years [70]. The other zoster vaccine Shingrix, a subunit vaccine containing VZV glycoprotein-E and the AS01B adjuvant, was approved by the Food and Drug Administration for adults $\geq 50$ years old in 2017 [71]. Since the advent of these vaccines, it was reported that the burden of $\mathrm{HZ}$ in the United States has begun to dissipate [72].

\section{TREATMENT}

Due to very limited literature and lack of random control trial studies of ZSH treatment, there are no guidelines about the treatment of ZSH at present. Once the diagnosis is established, it is reasonable to treat it with an antiviral agent (acyclovir or vacyclovir) combined with pain management (e.g., intercostal nerve block) and specialized treatment for various sequelae [1]. Furuta et al. [52] achieved a $100 \%$ cure rate of 13 facial palsy patients with $\mathrm{ZSH}$ after acyclovir-prednisone treatment. If no special sequela displayed, the treatment for ZSH can be the same as that for HZ [34]. The main purposes of HZ and ZSH treatment including pain relief, rapid healing, and avoiding sequela. Once a diagnosis is made, to reduce the intensity of acute pain and the duration and severity of reactivation, antivirals should be started as soon as possible [73]. Aciclovir, valaciclovir, or famciclovir can be used as the antiviral agents. Non-steroidal anti-inflammatory drugs, tramadol, opioids, ligands of the $\alpha 2 \delta$ subunit of the calcium channel (gabapentin or pregabalin), tricyclic antidepressants, or corticosteroids can be used to relieve herpetic neuralgia [73]. Other kinds of therapy include local management of skin lesions, epidural neural blockade, and traditional Chinese medicine [74]. Of note, in order to reduce the replication of VZV and the subsequent neuropathological damage, ZSH should be treated as soon as possible [75].

PHN also requires timely and active treatment when it is diagnosed. PHN should be considered and treated according to PHN guidelines [76] for patients with recurrent neuralgia at the same site. Long-term PHN torment can lead to complications such as anxiety and depression [77,78], and can cause structural and functional abnormalities in the brain of PHN patients [79-81].

\section{CONCLUSION AND FUTURE DIRECTIONS}

$\mathrm{ZSH}$, a special form of VZV reactivation, often leads to misdiagnosis due to the lack of typical clinical manifestations. ZSH should be considered in patients with unilateral, single-root neuralgia and diagnosed with VZV DNA and/ or anti-VZV IgG/IgM. As one sequela of ZSH, PHN should be considered and treated in patients with recurrent neuralgia in the same site. Accurate diagnosis method, timely antiviral therapy, more ZSH related studies and guidelines will be beneficial for ZSH diagnosis and treatment.

\section{CONFLICT OF INTEREST}

No potential conflict of interest relevant to this article was reported. 


\section{FUNDING}

No funding to declare.

\section{ORCID}

Junli Zhou, https://orcid.org/0000-0002-6034-6973

Juan Li, https://orcid.org/0000-0002-8430-9069

Lulin Ma, https://orcid.org/0000-0002-4680-9345

Song Cao, https://orcid.org/0000-0003-4619-9441

\section{REFERENCES}

1. Dayan RR, Peleg R. Herpes zoster - typical and atypical presentations. Postgrad Med 2017; 129: 567-71.

2. Nagel MA, Gilden DH. The protean neurologic manifestations of varicella-zoster virus infection. Cleve Clin J Med 2007; 74: 489-94, 496, 498-9 passim.

3. Kennedy PGE, Gershon AA. Clinical features of varicellazoster virus infection. Viruses 2018; 10: 609.

4. Jeon YH. Herpes zoster and postherpetic neuralgia: practical consideration for prevention and treatment. Korean J Pain 2015; 28: 177-84.

5. Lewis GW. Zoster sine herpete. Br Med J 1958; 2: 418-21.

6. Drago F, Herzum A, Ciccarese G, Broccolo F, Rebora A, Parodi A. Acute pain and postherpetic neuralgia related to varicella zoster virus reactivation: comparison between typical herpes zoster and zoster sine herpete. J Med Virol 2019; 91: 287-95.

7. Ibraheem M, Marin M, Leung J, Bryce CH, Schmid DS, Zaki SR, et al. Fatal wild-type varicella-zoster virus encephalitis without a rash in a vaccinated child. Pediatr Infect Dis J 2013; 32: 183-5.

8. Chen WH, Chui C, Yin HL. Zoster sine herpete, vertebral artery stenosis, and ischemic stroke. J Stroke Cerebrovasc Dis 2013; 22: e234-7.

9. Weaver BA. Herpes zoster overview: natural history and incidence. J Am Osteopath Assoc 2009; 109(6 Suppl 2): S2-6.

10. Takao Y, Miyazaki Y, Okeda M, Onishi F, Yano S, Gomi Y, et al. Incidences of herpes zoster and postherpetic neuralgia in Japanese adults aged 50 years and older from a communitybased prospective cohort study: the SHEZ study. J Epidemiol 2015; 25: 617-25.

11. Yang F, Yu S, Fan B, Liu Y, Chen YX, Kudel I, et al. The epidemiology of herpes zoster and postherpetic neuralgia in China: results from a cross-sectional study. Pain Ther 2019; 8: 249-59.

12. Tseng HF, Bruxvoort K, Ackerson B, Luo Y, Tanenbaum H, Tian Y, et al. The epidemiology of herpes zoster in immunocompetent, unvaccinated adults $\geq 50$ years old: incidence, complications, hospitalization, mortality, and recurrence. J Infect Dis 2019. doi: 10.1093/infdis/jiz652.

13. Johnson RW, Rice AS. Clinical practice. Postherpetic neuralgia. N Engl J Med 2014; 371: 1526-33.

14. Kawai K, Gebremeskel BG, Acosta CJ. Systematic review of incidence and complications of herpes zoster: towards a global perspective. BMJ Open 2014; 4: e004833.

15. Kawai K, Yawn BP, Wollan P, Harpaz R. Increasing incidence of herpes zoster over a 60-year period from a populationbased study. Clin Infect Dis 2016; 63: 221-6.

16. Gershon AA, Gershon MD, Breuer J, Levin MJ, Oaklander AL, Griffiths PD. Advances in the understanding of the pathogenesis and epidemiology of herpes zoster. J Clin Virol 2010; 48(Suppl 1): S2-7.

17. Koshy E, Mengting L, Kumar H, Jianbo W. Epidemiology, treatment and prevention of herpes zoster: a comprehensive review. Indian J Dermatol Venereol Leprol 2018; 84: 251-62.

18. Sauerbrei A. Diagnosis, antiviral therapy, and prophylaxis of varicella-zoster virus infections. Eur J Clin Microbiol Infect Dis 2016; 35: 723-34.

19. Gershon AA, Breuer J, Cohen JI, Cohrs RJ, Gershon MD, Gilden D, et al. Varicella zoster virus infection. Nat Rev Dis Primers 2015; 1: 15016.

20. McDonald JR, Zeringue AL, Caplan L, Ranganathan P, Xian $\mathrm{H}$, Burroughs TE, et al. Herpes zoster risk factors in a national cohort of veterans with rheumatoid arthritis. Clin Infect Dis 2009; 48: 1364-71.

21. Laemmle L, Goldstein RS, Kinchington PR. Modeling varicella zoster virus persistence and reactivation - closer to resolving a perplexing persistent state. Front Microbiol 2019; 10: 1634 .

22. Arvin A. Aging, immunity, and the varicella-zoster virus. $\mathrm{N}$ Engl J Med 2005; 352: 2266-7.

23. Wang JP, Kurt-Jones EA, Shin OS, Manchak MD, Levin MJ, Finberg RW. Varicella-zoster virus activates inflammatory cytokines in human monocytes and macrophages via Tolllike receptor 2. J Virol 2005; 79: 12658-66.

24. Hevner R, Vilela M, Rostomily R, Cohrs R, Mahalingam R, Wellish $\mathrm{M}$, et al. An unusual cause of trigeminal-distribution pain and tumour. Lancet Neurol 2003; 2: 567-71.

25. Birlea M, Nagel MA, Khmeleva N, Choe A, Kleinschmidt-Demasters B, Hevner R, et al. Varicella-zoster virus trigeminal ganglioneuritis without rash. Neurology 2014; 82: 90-2.

26. Zerboni L, Arvin A. Neuronal subtype and satellite cell tropism are determinants of varicella-zoster virus virulence in human dorsal root ganglia xenografts in vivo. PLoS Pathog 2015; 11: e1004989.

27. Furuta Y, Fukuda S, Suzuki S, Takasu T, Inuyama Y, Nagashima K. Detection of varicella-zoster virus DNA in patients with acute peripheral facial palsy by the polymerase chain reaction, and its use for early diagnosis of zoster sine herpete. J Med Virol 1997; 52: 316-9. 
28. Gershon AA, Gershon MD. The Jeremiah Metzger lecture varicella zoster virus: from outside to inside. Trans Am Clin Climatol Assoc 2016; 127: 282-99.

29. Gilden D, Cohrs RJ, Mahalingam R, Nagel MA. Neurological disease produced by varicella zoster virus reactivation without rash. Curr Top Microbiol Immunol 2010; 342: 243-53.

30. Galetta KM, Gilden D. Zeroing in on zoster: a tale of many disorders produced by one virus. J Neurol Sci 2015; 358: 38 45.

31. Kennedy PG. Zoster sine herpete: it would be rash to ignore it. Neurology 2011; 76: 416-7.

32. Edelman DA, Antaki F, Basson MD, Salwen WA, Gruber SA, Losanoff JE. Ogilvie syndrome and herpes zoster: case report and review of the literature. J Emerg Med 2010; 39: 696-700.

33. Gilden DH, Wright RR, Schneck SA, Gwaltney JM Jr, Mahalingam R. Zoster sine herpete, a clinical variant. Ann Neurol 1994; 35: 530-3.

34. Kasahara M, Ichinohe T, Sano T, Fukuda K, Kaneko Y. A case of zoster sine herpete of the trigeminal nerve. Bull Tokyo Dent Coll 2011; 52: 47-51.

35. Hosseini S, Zawawi F, Young J. Atypical presentation of a common disease: shingles of the larynx. J Voice 2015; 29: 600-2.

36. Sengoku R, Yaguchi H, Matsushima S, Mochio S. Zoster sine herpete: detection by skin exudates and contrast magnetic resonance imaging. Eur Neurol 2012; 67: 154.

37. Silverstein BE, Chandler D, Neger R, Margolis TP. Disciform keratitis: a case of herpes zoster sine herpete. Am J Ophthalmol 1997; 123: 254-5.

38. Gershon AA, Chen J, Gershon MD. Use of saliva to identify varicella zoster virus infection of the gut. Clin Infect Dis 2015; 61: 536-44.

39. Gershon AA, Gershon MD. Pathogenesis and current approaches to control of varicella-zoster virus infections. Clin Microbiol Rev 2013; 26: 728-43.

40. Leung J, Harpaz R, Baughman AL, Heath K, Loparev V, Vázquez $\mathrm{M}$, et al. Evaluation of laboratory methods for diagnosis of varicella. Clin Infect Dis 2010; 51: 23-32.

41. Quinlivan M, Sengupta N, Papaevangelou V, Sauerbrei A, Grillner L, Rousseva R, et al. Use of oral fluid to examine the molecular epidemiology of varicella zoster virus in the United Kingdom and continental Europe. J Infect Dis 2013; 207: 588-93.

42. Pahud BA, Glaser CA, Dekker CL, Arvin AM, Schmid DS. Varicella zoster disease of the central nervous system: epidemiological, clinical, and laboratory features 10 years after the introduction of the varicella vaccine. J Infect Dis 2011; 203: 316-23.

43. Papaevangelou V, Quinlivan M, Lockwood J, Papaloukas O, Sideri G, Critselis E, et al. Subclinical VZV reactivation in immunocompetent children hospitalized in the ICU associated with prolonged fever duration. Clin Microbiol Infect 2013; 19:
E245-51.

44. Tecellioglu M, Kamisli S, Erbay MF, Kamisli O, Ozcan C. A rare presentation of cranial polyneuropathy without rash caused by varicella zoster virus. Med Arch 2017; 71: 293-5.

45. Gershon AA. The history and mystery of VZV in saliva. J Infect Dis 2011; 204: 815-6.

46. Park SY, Kim JY, Kwon JS, Jeon NY, Kim MC, Chong YP, et al. Relationships of varicella zoster virus (VZV)-specific cellmediated immunity and persistence of VZV DNA in saliva and the development of postherpetic neuralgia in patients with herpes zoster. J Med Virol 2019; 91: 1995-2000.

47. Nahass GT, Penneys NS, Leonardi CL. The clinical spectrum from classic varicella zoster to zoster sine herpete: the missing link. Arch Dermatol 1992; 128: 1278-9.

48. Easton HG. Zoster sine herpete causing acute trigeminal neuralgia. Lancet 1970; 2: 1065-6.

49. Nagel MA, Gilden D. Neurological complications of varicella zoster virus reactivation. Curr Opin Neurol 2014; 27: 356-60.

50. Vena GA, Apruzzi D, Vestita M, Calvario A, Foti C, Cassano N. Zoster ... "almost" ... sine herpete: diagnostic utility of real time-polymerase chain reaction. New Microbiol 2010; 33: 409-10.

51. Lee HY, Kim MG, Park DC, Park MS, Byun JY, Yeo SG. Zoster sine herpete causing facial palsy. Am J Otolaryngol 2012; 33: 565-71.

52. Furuta Y, Ohtani F, Mesuda Y, Fukuda S, Inuyama Y. Early diagnosis of zoster sine herpete and antiviral therapy for the treatment of facial palsy. Neurology 2000; 55: 708-10.

53. Tamir B, Peleg R. Burning pain from chest to back · allodynia and hyperesthesia $\cdot$ extreme sensitivity at the left $\mathrm{T} 5$ dermatome $\cdot$ Dx? J Fam Pract 2015; 64: E1-2.

54. Morita Y, Osaki Y, Doi Y, Forghani B, Gilden DH. Chronic active VZV infection manifesting as zoster sine herpete, zoster paresis and myelopathy. J Neurol Sci 2003; 212: 7-9.

55. Nagel MA, Forghani B, Mahalingam R, Wellish MC, Cohrs RJ, Russman AN, et al. The value of detecting anti-VZV IgG antibody in CSF to diagnose VZV vasculopathy. Neurology 2007; 68: 1069-73.

56. Haug A, Mahalingam R, Cohrs RJ, Schmid DS, Corboy JR, Gilden D. Recurrent polymorphonuclear pleocytosis with increased red blood cells caused by varicella zoster virus infection of the central nervous system: case report and review of the literature. J Neurol Sci 2010; 292: 85-8.

57. Gilden D, Nagel MA, Ransohoff RM, Cohrs RJ, Mahalingam $\mathrm{R}$, Tanabe JL. Recurrent varicella zoster virus myelopathy. J Neurol Sci 2009; 276: 196-8.

58. Blumenthal DT, Shacham-Shmueli E, Bokstein F, Schmid DS, Cohrs RJ, Nagel MA, et al. Zoster sine herpete: virologic verification by detection of anti-VZV IgG antibody in CSF. Neurology 2011; 76: 484-5.

59. Amlie-Lefond C, Mackin GA, Ferguson M, Wright RR, Mahalingam R, Gilden DH. Another case of virologically con- 
firmed zoster sine herpete, with electrophysiologic correlation. J Neurovirol 1996; 2: 136-8.

60. Gilden DH, Kleinschmidt-DeMasters BK, LaGuardia JJ, Mahalingam R, Cohrs RJ. Neurologic complications of the reactivation of varicella-zoster virus. N Engl J Med 2000; 342: 635-45.

61. Pollak L, Mehta SK, Pierson DL, Sacagiu T, Avneri Kalmanovich S, Cohrs RJ. Varicella-zoster DNA in saliva of patients with meningoencephalitis: a preliminary study. Acta Neurol Scand 2015; 131: 417-21.

62. Yamada S, Atsuta N, Tokunaga S, Motegi Y. Ipsilateral truncal sensory deficit in a patient with ophthalmic zoster sine herpete. Neurology 2003; 60: 1049-50.

63. Mantero V, De Toni Franceschini L, Lillia N, Guccione A, Santilli I, Agostoni E. Varicella-zoster meningoencephaloradiculoneuropathy in an immunocompetent young woman. J Clin Virol 2013; 57: 361-2.

64. Spagnoli C, Cantalupo G, Piccolo B, Cerasti D, Pisani F. Unusual trigeminal autonomic pain heralding hemichorea due to zoster sine Herpete vasculopathy. Pediatr Neurol 2013; 49: 205-8.

65. Persson A, Bergström T, Lindh M, Namvar L, Studahl M. Varicella-zoster virus CNS disease--viral load, clinical manifestations and sequels. J Clin Virol 2009; 46: 249-53.

66. Dueland AN, Devlin M, Martin JR, Mahalingam R, Cohrs R, Manz H, et al. Fatal varicella-zoster virus meningoradiculitis without skin involvement. Ann Neurol 1991; 29: 569-72.

67. Kleinschmidt-DeMasters BK, Gilden DH. Varicella-zoster virus infections of the nervous system: clinical and pathologic correlates. Arch Pathol Lab Med 2001; 125: 770-80.

68. Philip A, Thakur R. Post herpetic neuralgia. J Palliat Med 2011; 14: 765-73.

69. Hadley GR, Gayle JA, Ripoll J, Jones MR, Argoff CE, Kaye RJ, et al. Post-herpetic neuralgia: a review. Curr Pain Headache Rep 2016; 20: 17.

70. Harpaz R, Ortega-Sanchez IR, Seward JF. Prevention of herpes zoster: recommendations of the Advisory Committee on Immunization Practices (ACIP). MMWR Recomm Rep 2008; 57: 1-30.
71. Dooling KL, Guo A, Patel M, Lee GM, Moore K, Belongia EA, et al. Recommendations of the Advisory Committee on Immunization Practices for use of herpes zoster vaccines. MMWR Morb Mortal Wkly Rep 2018; 67: 103-8.

72. Harpaz R, Leung JW. The epidemiology of herpes zoster in the United States during the era of varicella and herpes zoster vaccines: changing patterns among older adults. Clin Infect Dis 2019; 69: 341-4.

73. Gan EY, Tian EA, Tey HL. Management of herpes zoster and post-herpetic neuralgia. Am J Clin Dermatol 2013; 14: 77-85.

74. Hui F, Boyle E, Vayda E, Glazier RH. A randomized controlled trial of a multifaceted integrated complementary-alternative therapy for chronic herpes zoster-related pain. Altern Med Rev 2012; 17: 57-68.

75. Abdel-Aziz M, Azab NA, Khalifa B, Rashed M, Naguib N. The association of Varicella zoster virus reactivation with Bell's palsy in children. Int J Pediatr Otorhinolaryngol 2015; 79: 328-31.

76. Argoff CE. Review of current guidelines on the care of postherpetic neuralgia. Postgrad Med 2011; 123: 134-42.

77. Schlereth T, Heiland A, Breimhorst M, Féchir M, Kern U, Magerl W, et al. Association between pain, central sensitization and anxiety in postherpetic neuralgia. Eur J Pain 2015; 19: 193-201.

78. McCarberg B. Managing the comorbidities of postherpetic neuralgia. J Am Acad Nurse Pract 2003; 15(12 Suppl): 16-21.

79. Cao S, Li Y, Deng W, Qin B, Zhang Y, Xie P, et al. Local brain activity differences between herpes zoster and postherpetic neuralgia patients: a resting-state functional MRI study. Pain Physician 2017; 20: E687-99.

80. Cao S, Qin B, Zhang Y, Yuan J, Fu B, Xie P, et al. Herpes zoster chronification to postherpetic neuralgia induces brain activity and grey matter volume change. Am J Transl Res 2018; 10: 184-99.

81. Cao S, Song G, Zhang Y, Xie P, Tu Y, Li Y, et al. Abnormal local brain activity beyond the pain matrix in postherpetic neuralgia patients: a resting-state functional MRI study. Pain Physician 2017; 20: E303-14. 